\title{
Bill Boyd
}

\section{In conversation with David Tait}

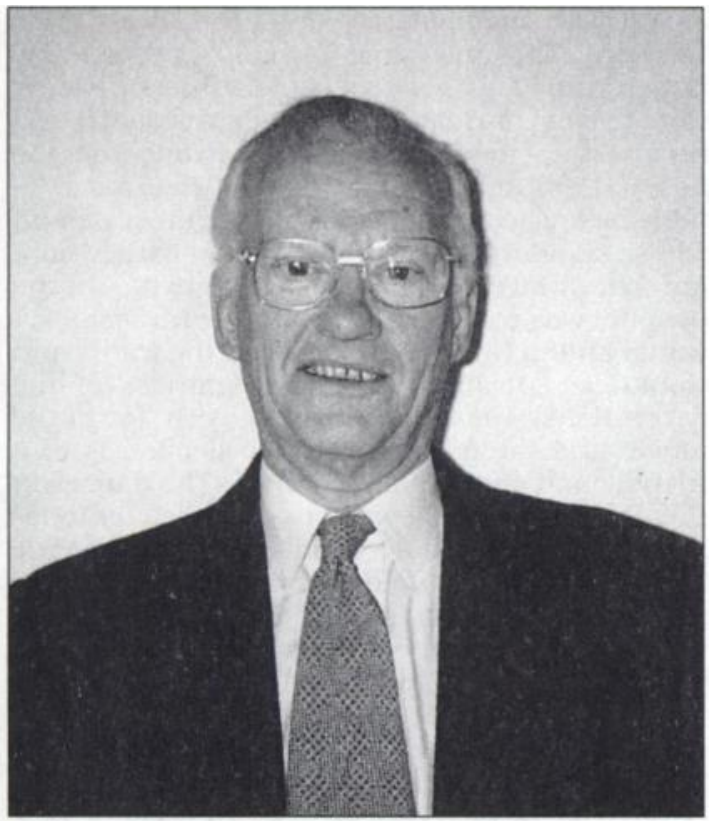

Bill Boyd

\section{Introduction (based upon an after- dinner speech by Bill Boyd shortly after his retirement)}

I was born in the Physician Superintendent's house, within the grounds of Fife and Kinross Asylum in 1930. My father had been appointed to the post of Physician Superintendent two years previously, at the age of thirty, and remained in the same job until his retirement in 1953.

The Asylum, which in keeping with changes in fashion would alter its name to Fife District Asylum, to Fife District Mental Hospital and finally to Stratheden Hospital, was situated only two and a half miles from Cupar, a busy market and county town, but the asylum formed an isolated and almost self-sufficient estate, with only tenuous links with local activities and local townsfolk.

\begin{abstract}
Bill Boyd is a second generation psychiatrist, having grown up in what is now Stratheden Hospital in Fife. His clinical career was largely in and around Edinburgh but always with a broader interest in Scottish psychiatry, leading to Chairmanship of the Scottish Division of the College and to the Mental Welfare Commission for Scotland. Having been involved in national affairs from the days of the Royal MedicoPsychological Association it was a further natural progression to become Treasurer of the College and to launch the Confidential Inquiry on behalf of the Department of Health. Dr Boyd has now retired, and was interviewed in his home in Edinburgh in December 1996.
\end{abstract}

The interests of staff and their families were concentrated on events within the asylum. It followed that from earliest memory I too was involved in many aspects of its day-to-day work and social life as I accompanied my father from one building to another or went walking in the grounds.

Memories still flood back with surprising ease, and it is perhaps remarkable, given present day views on the horror of the old-fashioned institutions, that these memories are almost entirely pleasurable. I suppose that as a very small child I held very firmly to my father's hand as we walked along the enormously long corridors, with their overpowering smell of paraffin wax floor polish and scent of paraldehyde, and as we stopped frequently, accosted by someone who wanted to discuss their treatment or even just to say hello to the 'wee sonny'. But it was not long before I was happy to run errands between the home and the 'office' without any sense of unease.

Particular moments in the daily activities remain very vivid. An important start to the day was the staff meeting in the office of the Physician Superintendent. The Matron, in full sail and accompanied by her pet dog, would be a regular member of the management team, as would the Chief Male Nurse, in dark suit with gold-braid arm-bands. These two senior nurses were rigidly confined in their responsibility to the 'Male Side' and the 'Female Side', and it was a major step forward when, after several years, the Matron took on responsibilities for the Nursing 
Service of the whole hospital. Also at the morning meeting would be the two Assistant Medical Officers. Letters would be opened and discussed, night reports would be studied in detail, and any matters affecting the general health of the institution would be dealt with, after which the individual doctors and nurses would go off on their rounds.

The duties of the Physician Superintendent seemed to be legion; it must be remembered that in these years before the Second World War the doctor-in-charge had full responsibility for the proper physical and psychiatric care of all the patients. He had often seen individuals at home before their admission and knew their full clinical history. My father prided himself on his ability to greet every patient by name and to recall the background of every patient under his care. When someone was ill and requiring medicine, a linctus for cough or powder for fever, this sometimes necessitated a visit to the dispensary in the evening - an Ali Baba cave of bottles and jars and of wonderful smells!

But beyond the clinical work came other activities which would see me accompanying my father to Cupar to meet the Secretary of the Committee. In those days the duties of the Secretary and Treasurer were carried out by a local lawyer on part-time basis, no doubt supported by an assistant clerk, but most of the spade-work would already have been carried out by the Physician Superintendent. The advent of a full-time Secretary and Treasurer, based in the hospital buildings, was seen as a rather expensive and unnecessary intrusion when this officer was appointed, probably at the beginning of the National Health Service in 1948. Presumably in earlier times there were fewer financial transactions to be undertaken. Certainly, the Physician Superintendent dealt with the accounting for all patients' valuables and monies, security being provided by a small wall safe in the office.

Sunday afternoon was the time to visit the hospital farm and dairies. The Farm Steward would be waiting to report on the state of the local agriculture, the milk yield, the slaughter house returns or the activities of the labour squads. The newly installed sewage plant was a source of great pride and satisfaction, though I never followed up the statement that the endproduct of the filtration plant was fit for drinking.

I mentioned earlier the self-sufficiency of the hospital estate; this was exemplified by the full range of skdled tradesmen whose individual workshops were always friendly places, open to visitors. Usually the individual artisans were supported by a patient-helper, but occasionally I found it possible to be accepted as a junior member of the team, and it brought an enormous sense of self-importance for a 10-year-old to take on the role of plumber's mate. How many colleagues, I wonder, had the opportunity of melting lead for pipe joints or of understanding the mechanisms of a lavatory cistern at this stage of their life?

But what of patient contact? I was taught from a very early age that the residents of the hospital, all one thousand of them, must be seen as individuals and that their personal idiosyncrasies or mannerisms must be dealt with tactfully. The only time I would ever see my father ruffled was when he felt that outsiders were teasing or ridiculing hospital residents, and he would not hesitate to exclude anyone from the hospital grounds if their attitude was unacceptable or to sack on the spot any member of stafi whose standard of behaviour did not satisfy him. My own involvement in the social activities of the hospital was considerable; from the earliest age I would attend Christmas parties in the wards and would be entranced by the brightness of the decorations, the tables spread with food, the music and the dancing. My recollection is of a friendly and cheerful atmosphere. The dances in the Recreation Hall were on a much grander scale and much more formal. The Chief Male Nurse in full gold-braid was Master of Ceremonies and took command of the evening. Patients were marshalled on two sides of the hall, males to the left. females to the right, everyone sitting down, but with an obvious air of expectancy. The band struck up, the Chief Male Nurse shouted "Gentlemen, take your partners" and the hall erupted as the men took off at a run to claim their partners. Some would be old-time sweethearts whose courtship was confined to these occasions, some would be making their first steps in learning social skills, some always made a beeline to have a dance with the doctor's wife and sometimes, horror, I would be invited by some unknown lady to partner her in a quickstep. Perhaps I was fortunate in having such an early introduction to the skills of ballroom dancing.

From time to time I would attend hospital concerts. These would be performed by groups from outside the hospital who voluntarily provided entertainment of rather variable quality. Sometimes, however, the evening was presented by patients and staff, giving opportunities for much hilarity and applause. One or two of the performers, not necessarily the most proficient, enjoyed their moment of glory, providing unwanted encores until they had to be gently removed from the stage while still in full tuneless voice.

Other happy moments crowd back on me as I write - the annual sports day, with brass band and masses of buns and lemonade, the inauguration of regular film shows with a full size cine projector presented by the local cinema owner, the opening of a shop/cafe in the hospital 
grounds to which in-patients and their relatives could go for tea. I was aware that for my father these were important milestones in the development of the hospital and that they gave him enormous personal satisfaction. His excitement over other attainments may seem strange today - over the opportunity to allow patients to dress in their own clothes, over the first occasion when turkeys could be provided for Christmas dinner, or over the day when coal for the hospital boilerhouse could be brought from the local station by lorry instead of by the horses and carts which had previously served this purpose.

I suppose that an era came to an end with the outbreak of the war in 1939, and in the peace which followed there were staff changes and service developments which culminated in the advent of the National Health Service in 1948. My impression of how people reacted to the forthcoming changes was that there was a huge sense of optimism that mental hospital practice would now be integrated with other medical specialities and that a national service would rise above narrow parochial interests and would permit more adequate funding. Psychiatry had come of age!

We shall come back to that unique experience of growing up in a psychiatric hospital, but I wonder whether that had anything to do with your choice of medicine as a career?

I suppose it did. I was brought up in a medical atmosphere and was so much involved with hospital life that I had really no other thoughts but that I would go into medicine. All that held me back was that I found myself half-way through my school career with classics as my subjects and very little knowledge of science.

And I gather your entry into psychiatry was a little unusual?

Yes, when I joined the Army to do my National Service in the Royal Army Medical Corps they asked everyone whether they had any previous experience of a speciality. I had only done my house jobs but at least I could spell the word, and had the background, so I said that I was interested in psychiatry. The result was that I was posted to Japan to British Commonwealth Forces Korea to be, believe it or not, Command Psychiatrist.

When you left the RAMC in 1957 you moved to Rosslynlee Hospital outside Edinburgh. What was it like returning to an asylum?

It was very comforting and comfortable because Rosslynlee was still traditional under a very excellent and benign Physician Superintendent, Dr Andy Hegarty, I found I was accepted there very easily. There was a very informal, warm atmosphere amongst doctors, nurses and all the staff and there was a lot going on there too - outpatient clinics in the local towns, patients coming up as day-patients, looking back now the services were remarkably advanced.

You seem to be suggesting that Care in the Community was not invented in the 1990s?

I certainly am suggesting that. Throughout my career consultant psychiatrists were doing their very best to move people who were capable of it into the community, to hostels, to residential care and most commonly back to their home, coming up to different units on a day-patient basis.

Much later on when I was Chairman of the Scottish Division, we were accused in Scotland of not being as advanced as the south in terms of cutting back on beds and putting people into the community. I remember very clearly writing to the Scotsman on behalf of the Division pointing out that psychiatrists were at the forefront of developing Care in the Community but that we as a group were not prepared to put our patients out of hospital until we were confident that community facilities and indeed public attitudes had matured to a level where it was reasonable to move our patients into Community Care. That was something which I felt very strongly about at that time and still do.

And of course that is now enshrined in good practice and in law.

You went to the Royal Edinburgh Hospital for further training in 1960. My peers see the seventies as the golden age in Edinburgh but I believe the early sixties were equally exciting, with a number of worldfamous psychiatrists working there at the time.

Yes, I would suggest that major changes began in the sixties which continued into the seventies. 1 joined the staff of the Royal Edinburgh Hospital just in the last few months of Professor Kennedy's life. I remember he stood at the front door of the old Jordanburn Clinic building, showing me with dramatic gestures where a new tower, a new professorial unit and a new clinic were going to go. It sounded like an unlikely dream but within a year or two the buildings were completed. Following his untimely death people who influenced me were first of all Frank Fish who had a very formal didactic style of presenting psychiatry, based very much on the German model but one which was quite unforgettable. He was followed by Morris Carstairs who arrived as the new Professor just after he had delivered his famous Reith lecture on 'Charity not Chastity'. 
His worldwide contacts and eclectic approach to psychiatry ensured that the expanding facilities in the hospital and University Department attracted overseas postgraduate students and a number of highly-respected senior psychiatrists to Edinburgh.

Your first consultant post was in Herdmanflat Hospital, again outside Edinburgh, from 1964 as the only consultant. Again, although the service was firmly based upon the hospital, there was a clear community orientation and I understand you were supported in this by Max Jones, then working in Dingleton.

Going down to East Lothian to work at Herdmanflat Hospital was like being allowed out to play because instead of all the constraints which I had experienced up to then I had my own ideas of how I would like to see a psychiatric service develop. Here was a golden opportunity to do so and to work with staff who were old-fashioned in their attitudes and expectations but who were competent and willing to change. Much of the work was community based and in the small catchment area of East Lothian I very quickly knew every general practitioner. I visited them in their consulting rooms and held clinics in small towns around the county which meant that I could see patients who might otherwise not have considered coming up to the hospital in Haddington. When I looked at the records of patients seen by me at that time. I found that the number of patients with psychoses, mainly manicdepressive illness and schizophrenia, in a series of out-patients was probably only $20 \%$ and the remainder were suffering from a whole range of other disorders. Evidently we were providing more than a psychosis service.

The bulk of your consultant career was of course back in the Royal Edinburgh Hospital from 1969 until 1984. This started with general psychiatry but with a shift to the psychiatry of old age, which was then developing as a specialty in its own right. In addition you assumed more management responsibility. first as Jim Affleck's Deputy and then as Physician Supertintendent. What particular themes stand out from those years in the Royal Edinburgh?

There were many rapid and dramatic changes at the Royal Edinburgh over these years. Numbers of consultants were significantly increasing in the sixties, thus allowing a steady reduction in the number of acute patients supervised by general psychiatrists and an increase in specialist posts. We realised that the numbers of elderly patients coming into the hospital were very considerable and this coincided with a wish to develop a better service for the treatment of patients with chronic psychotic illness. Under the leadership of Jim Affleck we came to a decision that it would be worth dividing the long-stay wards in a fairly arbitrary way into those for treatment of chronic psychosis and those for disorders of old age. Almost on the spin of a coin, but partly because of Alistair Forrest's interest in psychosis. I took it upon myself to organise the service for elderly people and later the major part of my job became care of the elderly.

Like you I grew up in a mental hospital and would confirm that far from being impersonal institutions they treated their patients as individuals and with great humanity. By the time you left the Royal Edinburgh was that still the case?

I am sure that individual consultants and teams were still treating the patients as individuals but what struck me, or what strikes me looking back on that time, was the extent to which people seemed to be involved in so many other activities that it was difficult to spend adequate time considering individual cases. We had developed a system where the ward round was where individual cases were considered but in an office situation where it was very difficult for the consultant to have personal contact with individual patients. Each consultant also now had an area of work which might be geographically separate from the hospital, taking time away from the centre. I always worried a little that we could no longer learn so much from each other over the coffee table, with less opportunity to talk informally about tricky problems of treatment and management.

You perhaps suggest that a Community Mental Health Team isolated from colleagues would be an inappropriate model for the future?

Yes, if this reduces the chance of sharing expertise and advances in treatment with other consultants. However, I have very clear memories of the advantage of turning the previous relationship between consultant and other staff into a close-knit working group with pooled knowledge, sharing the care of patients. I remember our first day hospital for the elderly which, despite being structurally quite wrong for the purpose, succeeded because of an excellent team of doctor, nurses, social worker, occupational therapist and health visitor.

You moved to the Mental Welfare Commission in 1984 and served it for the next seven years. What led you to make that move and what do you feel you contributed to the welfare of psychiatric patients in Scotland over those years? 
Well, the first part of that question is easily enough answered. I had only been Physician Superintendent for some four years but had been Deputy before that and I had worked at the hospital since 1960, so that I did feel that it was time to have a change. I was attracted to the Mental Welfare Commission because of the new Mental Health Act coming in at the time, giving the Commission a fresh approach, and I realised that there was an acceptance at that time amongst clinicians that the Commission could offer advice and could help to transfer new ideas from one area of Scotland to another.

The second part of the question is more difficult to answer. I would like to think that some of the themes which evolved in the work in the Commission meant that there was discussion in all sorts of different situations with all sorts of different people. Some of these ideas, for example getting the balance right between the compulsory care that some patients required, and a more informal approach, was something which I hope I contributed to. I think this was also particularly important in relation to the further development of community care where there was conflict between the views of the established consultant psychiatrists and an alternative view often put forward by nonmedical, non-professional people who claimed to speak on behalf of patients. Personally, I always thought that one of the most important jobs for a psychiatrist was to speak on behalf of patients and I still think that we do that quite effectively.

You have spoken of team work within psychiatry, you have expressed a little concern about those who would speak for patients, but you have been very involved with the voluntary sector who actually work for, and with, patients. This includes the Scottish Association for Mental Health, Edinburgh and Leith Old People's Welfare Council, Age Concern Scotland and Music in Hospitals. How did you become involved with these organisations?

It arose very much through my work. My interest in the Scottish Association for Mental Health went back to the Herdmanflat days when the local association was very interested in trying to support the hospital and in providing extra services for it, I knew them very well and worked closely with them. In terms of voluntary care for the elderly, this developed directly from working in the hospital, dealing with relatives, recognising that they had great needs which deserved to be discussed and heard, and helping to set up first of all a local relatives' group. I became involved with Edinburgh and Leith Old People's Welfare Council because I was invited to do so, and I saw very quickly what a lot was being done for old people in Edinburgh generally, quite apart from those whom I was seeing. I recognised that the voluntary association did have something to contribute in quite a practical way, namely in helping to organise care for mildly demented people; one thing I enjoyed very much was setting up a purpose-built day centre for old people suffering from dementia which I am glad to say is still a very thriving and successful concern.

From there I moved on to Age Concern Scotland which of course was dealing in a much broader way with the needs of the elderly, but there was sufficient worry about the more frail, including the demented members of society, that I still felt that there was a direct link between the work which could be done in the voluntary sector and the more formal work of the Health Service. Music in Hospitals is of a different dimension. I heard about Music in Hospitals only because they came into a ward which I was responsible for in the Royal Edinburgh Hospital to have a concert and I wandered in as I was passing by. I was enormously impressed with the extent to which the singer and the accordionist there made contact with patients, including a particularly paranoid and difficult elderly Italian man whom I had been responsible for bringing into hospital under Certificate a few days before. They were able to make such an impact that I thought this is magnificent, this is marvellous, this is something which I must know more about and when you say things like that you usually end up on a committee which is exactly what happened to me. I am still involved and I still think it is a most wonderful help to people in hospital, in hostels and other establishments visited by professional musicians from Music in Hospitals.

So far we have concentrated on the Scottish part of your career. This also included long service to the Scottish Division of the College, culminating in your Chairmanship, and you have also served on Council, on Executive and Finance and on the Education Committee of the College. In 1986 however you reached the dizzy heights of Treasurer, visiting Belgrave Square regularly, how do you see the evolution of our College over the last 10 years?

I should probably say that even before the College was founded I was elected as what was then called the Junior Representative on Council of the old Royal Medico-Psychological Association and began going down to London then on a regular basis albeit having to pay my expenses out of my own pocket at the time! Perhaps that was quite good training for me later in my career as Treasurer of the Collegel It has been a long evolution-increasing activities, greater demands, more expectations from the members, more expectations from the public about what pronouncements should come out of Belgrave 
Square, more involvement in political matters, more involvement with NHS matters at local and national level, a need for more staff in the College and therefore a need for more resources, but all this is happening in a very exciting way.

Your final professional contribution has been as Director of the Confidential Inquiry into homicide and suicide among mentally ill people, this initiative of course continues. We have discussed elsewhere the questions of paternalism, sometimes used almost as a term of abuse, whereas the proper role of parents is of course to promote the autonomy of their offspring. Perhaps this theme pervades your career but is most graphically illustrated in the question of homicide and suicide - to what extent we seek to protect vulnerable people, and how we balance that with taking calculated risks which allow and promote their autonomy. Are you any clearer now than you were forty years ago where that balance should best lie?

I think that what emerged most clearly in the Confidential Inquiry was that the balance between protection, over-protection and underprotection of the individual patient was a very, very delicate line. Perhaps the problem is quite a personal one for individual clinicians because there are those of us who are sufficiently anxious about our patients that we over-protect them and there are those of us who are sufficiently lax, and one might even say careless, that we underprotect our patients. I guess that it is at those two extremes that it should be possible to improve matters. One of the depressing things that I found in doing this Inquiry was that there were so many themes which came back to me in the questionnaires which people so kindly returned, which have already been gone over in other inquiries into individual cases. As we said in the report of the Inquiry, lessons had been learnt and forgotten, then re-learnt and forgotten again. and I suppose all we can do is keep looking and looking again and re-assessing situations our- selves. That perhaps takes me back to the value of close contact amongst clinicians to keep discussing the level of supervision and care which is appropriate for our patients.

Although you have now retired completely from psychiatry you remain in touch with former colleagues socially and retain a keen interest in developments in Mental Health Services. Are you hopeful for the future of psychiatry in Scotland?

Yes, I am entirely hopeful for the future. I have always been interested in the evolution of psychiatry and have inevitably read widely about local heroes, Thomas Clouston and George Robertson, earlier Physician Superintendents of the Royal Edinburgh and of course many others who have gone before them. What has always impressed me is the vision of these people in providing a level of excellence in the care of their patients wherever psychiatric knowledge happened to be at the time. They were always pushing things forward, always having new visions of what might be accomplished and I think that at the present time colleagues in psychiatry are still full of ideas of what can be done to make psychiatric services more effective. I do regret that over the years their involvement in so many non-clinical duties and in the neverending changes in management structures since 1974. have taken an immense amount of individual clinicians' time away from the patients. The findings of the Confidential Inquiry strengthened my conviction that the best treatment we can offer patients, whatever their diagnosis, is an adequate supply of high quality patient-therapist time, and that in many instances this is not made avallable. I believe that if only the Health Service can be allowed to run in a state of reasonable equilibrium then the enthusiasm and the quality of Scottish psychiatrists will ensure the best future for people with psychiatric illness. 